\title{
Genetic Parameters of Milk Production Traits in Crossbred Cows in Ethiopia
}

\author{
K. Getahun*, M. Tadesse, D. Hunde, Z. Lemma
}

Ethiopian Institute of Agricultural Research, Holetta Research Center P O Box 2003 Addis Ababa or 31 Holetta, Ethiopia

*Corresponding author email: kefalegetahun@gmail.com

Journal of Livestock Science (ISSN online 2277-6214) 12: 103-110

Received on 22/12/20; Accepted on 25/2/21; Published on 28/2/21

doi. 10.33259/JLivestSci.2021.103-110

\begin{abstract}
Variance components and genetic parameters are essential tool in animal breeding research and in the design and application of practical breeding programs. Genetic improvement of milk yield and lactation length in dairy cows greatly depends on the phenotypic and genetic variability, heritability and correlation between these traits. The aim of this study was to generate recent information on genetic parameters (heritability, repeatability, genetic and phenotypic correlations and genetic trends) of some economic traits of Borana and its crosses with Holstein Friesian dairy cattle. Overall, 8123 dairy cattle performance records were used for this study. WOMBAT, which is a software package for quantitative genetic analyses of continuous traits, fitting a linear, mixed model; estimates of (co)variance components and the resulting genetic parameters (heritability, repeatability, genetic and phenotypic correlation) were employed and obtained. However, regression analysis was used for estimation of genetic trend by using SAS software. The estimated heritability values for the three production traits were $0.24,0.28$ and 0.12 for lactation milk yield (LMY), daily milk yield (DMY) and lactation length (LL), respectively. Repeatability estimate for LMY and DMY were medium (0.50 and 0.46$)$ but for LL, it was low (0.23). The genetic correlation among milk traits in the present study were positive and low (0.11 between LMY and DMY), moderate between DMY and LL (0.54), and slightly high (0.77 between LMY and LL). However, phenotypic correlation among these traits was very low (0.069 between DMY and LMY), low (0.18 between DMY and LL) and moderately low ( 0.36 between LMY and LL). Based on genetic trend analysis, the estimated annual gain/change for LMY, DMY and LL were -0.29 liter/year, 0.0015x-2.9 liter/year and 0.038x-74 days/year, respectively. Genetic parameter estimation in the present study had a promising result for milk production traits, which can be further improved by giving particular emphasis for management and continuing to create genetic variability of this herd.
\end{abstract}

Keywords: crossbred dairy cattle; genetic parameter; genetic trend; Ethiopia 


\section{Introduction}

The majority of tropical (indigenous) cattle are low producers of milk with high individual variability, which is attributed to natural selection to the tropical environment and management (Dechow et al., 2001). To improve their performance, the introduction of high-yielding breeds (Holstein-Friesian, Jersey, and Simmental) have been playing an important role. However, the performance of these breeds are often affected due to genotypeenvironment interactions (Ojango et al., 2006; Gebregziabher et al., 2014).

Crossbreeding of tropical indigenous breeds with temperate dairy breeds has been used in various countries as a mean of increasing milk production (Cunningham and Syrstad, 1987) and total selection indexes have been initially, emphasized on milk production traits (Dash et al, 2016). Miglior et al. (2005) surveyed the selection indexes of 15 countries from different geographical regions and showed that the average relative emphasis for production across all countries was $59.5 \%$. This finding indicated that milk production is still the most important component of selection indexes used in dairy cattle.

Borana breed is one of the tropical indigenous breed and a group of large east African Zebu cattle (Bos indicus), widely distributed across various countries of Africa (DAGRIS, 2006). The breed has a high degree of heat and diseases tolerance prevailing in the tropics and the ability to survive long periods of feed and water shortage, which able to well adapted to semiarid tropical conditions (Ojango et al., 2006). The breed is characterized as improved and unimproved type. The unimproved Boran is used in subsistence and semi commercial systems of production in Ethiopia, Kenya and Somali where it is commonly called Borana, Boran and Awai, respectively (Ojango et al. 2006). The Ethiopian Borana, presently found in the Borena, Ogaden, Sidama and Bale areas of Ethiopia and the adjoining regions of Somalia and Kenya which is known with their hump, pendulous dewlap and, very short, erect and thick horn at the base pointing forward. The color is mainly white, light gray, fawn or light brown with gray, black or dark brown shading on head, neck, shoulders and hindquarters. Average wither height is 118 to $124 \mathrm{~cm}$ in males and 116 to $120 \mathrm{~cm}$ in females. Body weight ranges from 318 to $680 \mathrm{~kg}$ in males and 225 to $454 \mathrm{~kg}$ in female (Alberro and Haile-Mariam 1982). The Borana has been used as one of the preferred dam breed in the dairy cattle crossbreeding and genetic improvement studies in Ethiopia over the last six decades. Their crossbred has been found to be fast growing, fertile and good milk producer compared to other indigenous breeds in Ethiopia (Aynalem et al., 2011). The genetic variances, heritability and repeatability estimates of pure Borana and their crosses are important aspect for the crossbreeding as well as pure breeding program in Ethiopia (Demeke et al., 2003; 2004; Haile et al., 2009).

Variance components and genetic parameters are essential tool in animal breeding research and in the design and application of practical breeding programs. Genetic improvement of milk yield and lactation length in dairy cows greatly depends on the phenotypic and genetic variability, heritability and correlation between these traits.

Heritability is important among the several factors determining how much genetic improvement can be made in any trait and important for selection of polygenic traits (Aynalem, 2006). heritability value for production traits like milk yield tend to vary more in the tropics than in the temperate region, which indicates the difference that in the additive, environmental and random error variance components between the two ecological regions (Chagunda, 2004).

Milk traits of dairy cows are repeated over time. With repeat measurements of the same trait, it can be possible to calculate the repeatability estimate, which in fact is the fraction of variance that is due to permanent difference between individuals. In dairy cattle, the measure of repeatability estimate refers to strength of the relationship or correlation between repeated records for a trait in a population and this may be utilized to assess the real producing ability of individual cows in a population (Olawumi and Salako, 2010). Different estimates of genetic parameters may be found for the same trait in different populations or in one population at different times.

Study on genetic parameter estimation for milk traits in Ethiopia was scanty because lack of organized animal data from the national level. Demeke et al. (2004) was estimated genetic parameters for production traits of crossbred dairy cattle by using parts of the center data. Data obtained from small herd size (small number of records) might distort the estimation of genetic parameters and genetic parameters have not a biological constant due to environmental variability, ongoing selection and use of different sires to create genetic variation in the farm and, there needs to be estimate by including large and updated data. Therefore, the objective of this study was thus to estimate variance components and genetic parameters for LMY, DMY and LL traits using a multivariate repeatability animal model. 


\section{Materials and methods}

Description of the study area

This research was conducted at Holetta Agricultural Research Center (HARC). Holetta is located in the central highland of Ethiopia at $29 \mathrm{~km}$ west of Addis Ababa $\left(9^{0} 00^{\prime} \mathrm{N}\right.$ latitude and $38^{0} 30^{\prime} \mathrm{E}$ longitude) with an altitude of 2400 meter above sea level (Getahun et al, 2020). The detailed environmental description of the study area was described by (Getahun et al, 2019; 2020).

Data source and collection

Data for the study was obtained from long-term (1974 - 2017) crossbred research of dairy cattle herd of Ethiopian Borana x HF (Holstein Friesian) crossbred dairy cattle maintained at the research station and therefore, Borana and different crossbred ranging from $50 \%$ to $75 \%$ of HF blood levels were used in this study.

Animal management

The cattle were managed based on breed, pregnancy, lactation stage, sex and age. Uniform feeding and management practices were adopted for all animals within each category. Natural grazing, hay and concentrate supplement constitute the major feed supply. The detail animal management system which undertaken in the research farm was described by (Getahun et al., 2019; 2020).

Breeding program

The $50 \% \mathrm{~F}_{1}$ generations (Borana $\mathrm{x}$ Holstein Friesian) were produced by mating of pure Borana dam and pure Friesian sire. On the other hand, $50 \% \mathrm{~F}_{1}$ is backcrossed with pure Friesian semen to produce the $75 \%$ first generation. The later generations, $\mathrm{F}_{2}\left(\mathrm{~F}_{1}\right.$ male $\mathrm{x} \mathrm{F}_{1}$ female $)$ and $\mathrm{F}_{3}\left(\mathrm{~F}_{2}\right.$ male $\mathrm{x} \mathrm{F}_{2}$ female $)$ were produced by inter se mating $50 \%$ male with $50 \%$ female and $75 \%$ male with $75 \%$ female to produce synthetic breed at $50 \% \mathrm{HF}$ (Holstein Friesian) and 50\% Borana and 75\% $\mathrm{HF}$ and $25 \%$ Borana blood levels. The detail breeding program which undertaken in the research farm was described by (Getahun et al., 2019; 2020).

Method of data analysis

Screenings of data were made to avoid manmade errors during data entrance on individual animal card or in the computer writing. The minimum truncation point for LL was 100 days, which regarded as incomplete lactation for analysis of LMY, DMY and LL. Lactation records of above eighth parities were pooled together in parity eight because of few records. The animals that have abnormal calving, i.e., abortions and stillbirths were not included in the analysis of breeding data. Records of animals without pedigree information and dates of birth and calving were excluded. Animals ID (name) that appeared before their parents were edited and recoded for the pedigree analysis.

Multivariate analysis for three traits (LMY, DMY and LL) were undertaken for estimation. WOMBAT genetic analysis software package version 01-11-2019, which is developed by Karin Meyer was used to determine variance components and genetic parameters (heritability, repeatability and genetic correlations).

Table 1. Number of records used for genetic analysis.

\begin{tabular}{|l|l|l|l|l|l|l|l|}
\hline \multirow{2}{*}{ Observed Traits } & \multicolumn{6}{|l|}{ Number of observations in each genetic group } & \multirow{2}{*}{ Total } \\
\cline { 2 - 8 } & \multirow{2}{*}{ Borana } & $50 \%$ & $75 \%$ & \\
\cline { 2 - 7 } & & F1 & F2 & F3 & F1 & F2 & \\
\hline Lactation milk yield & 482 & 1598 & 234 & 139 & 299 & 43 & 2795 \\
\hline Daily milk yield & 478 & 1543 & 234 & 139 & 236 & 34 & 2664 \\
\hline Lactation length & 478 & 1543 & 234 & 139 & 236 & 34 & 2664 \\
\hline Total & 1438 & 4684 & 702 & 417 & 771 & 111 & 8123 \\
\hline
\end{tabular}

Year, season, parity and breed (genetic group) were fitted as a fixed effect in the model. Months of the years were classified into 3 seasons based on rainfall distribution. Dry season from October to February, short rain season from March to May and main rain season from June to September. direct additive effects plus permanent environmental effect due to repeated records per cow were fitted as random effects. The model was presented as follows in a matrix notation;

$$
\mathrm{Y}=\mathrm{Xb}+\mathrm{Z}_{\mathrm{a}}+\mathrm{W}_{\mathrm{d}}+\mathrm{e} . \text { where }
$$

$\mathrm{Y}$, is a vector of observations for the traits of interest (LMY, DMY and LL)

$\mathrm{b}$, is a vector of fixed effects (breed/genetic group, year, season and parity).

$\mathrm{a}$, is a vector of random individual additive effects

$\mathrm{d}$, is a vector of permanent environmental effects 
$\mathrm{X}$, matrices relating records to fixed effects

$\mathrm{Z}$, matrices relating records to incidence random individual additive effect

$\mathrm{W}$, matrices of permanent environmental effects.

e, vector of random residual effect

This model was assumed as expected value of $\mathrm{Y}$ to be $\mathrm{Xb}$. The vector random individual additive effects, permanent environmental effects and residual effects are assumed to be uncorrelated and have expected mean of zero and variances $\sigma_{\mathrm{a}}^{2}, \sigma_{\mathrm{c}}^{2}$ and $\sigma_{\mathrm{e}}^{2}$, respectively. From these expectations, WOMBAT is estimated the direct (co) variance, heritability, repeatability, genetic and phenotypic correlations and breeding values of each animal for each trait from multigenerational pedigree data as the software already recognized the following formulas.

$\sigma_{\mathrm{p}}^{2}=\sigma_{\mathrm{a}}^{2}+\sigma_{\mathrm{c}}^{2}+\sigma_{\mathrm{e}}^{2}$

$\mathrm{h}^{2}=\sigma_{\mathrm{a}}^{2} / \sigma_{\mathrm{p}}^{2}$

$\mathrm{r}^{2}=\sigma_{\mathrm{a}}^{2}+\sigma_{\mathrm{c}}^{2} / \sigma_{\mathrm{p}}^{2}$

$\mathrm{h}^{2}$; Heritability value

$\mathrm{r}^{2}$; Repeatability value

$\sigma_{\mathrm{p}}^{2}$; is phenotypic (total variance)

$\sigma_{\mathrm{a}}^{2}$; Additive genetic variance

$\sigma_{\mathrm{c}}^{2} ;$ Permanent environmental variance

$\sigma_{\mathrm{e}}^{2}$; Residual variance

$$
\begin{aligned}
& r_{g}=\sigma_{\text {aij }} / \sqrt{a i} \sigma_{a j}^{2} \sigma_{a j}^{2} \\
& r_{p=} \sigma_{p i j} / \sqrt{\sigma_{p i}^{2}} \sigma_{p j}^{2}
\end{aligned}
$$

$\mathrm{r}_{\mathrm{g}}$; genetic correlations

$$
\mathrm{r}_{\mathrm{p}} \text {; phenotypic correlations }
$$

$\sigma_{\text {aij }}$; Additive genetic covariance between trait $\mathrm{i}$ and $\mathrm{j}$

$\sigma_{\mathrm{pij}} ;$ Phenotypic covariance between trait i and $\mathrm{j}$

$\sigma_{\mathrm{ai}}^{2}$; Additive genetic variance for trait $\mathrm{i}$

$\sigma_{a j}^{2}$; Additive genetic variance for trait $\mathrm{j}$

$\sigma_{\mathrm{pi}}^{2}$; Phenotypic variance for trait i

$\sigma_{\mathrm{pj}}^{2}$; Phenotypic variance for trait $\mathrm{j}$

Table 2. Number of records on pedigree characteristics for genetic parameter analysis.

\begin{tabular}{|l|l|l|}
\hline No & Pedigree characteristics & Records \\
\hline 1 & Number of animal IDs in data file & 1095 \\
\hline 2 & Number of animal IDs in total & 1299 \\
\hline 3 & Number of animals without offspring & 667 \\
\hline 4 & Number of animals with offspring & 535 \\
\hline 5 & Number of animals with unknown sire & 376 \\
\hline 6 & Number of animals with unknown dam & 413 \\
\hline 7 & Number of animals with both parents unknown & 355 \\
\hline 8 & Number of sires with progeny in the data & 96 \\
\hline 9 & Number of dams with progeny in the data & 439 \\
\hline 10 & Number of animals with maternal grandsire & 342 \\
\hline 11 & Number of animals with maternal grand dam & 313 \\
\hline
\end{tabular}

Regression analysis was used to estimate genetic trends for LMY, DMY and LL using SAS 2004 version 9.0. The overall additive genetic trend in a trait was estimated by regressing the mean predicted breeding values on the respective year of birth in each trait (Rege and Mosi, 1989). 


\section{Results and Discussion}

Heritability estimation

Estimates for variance components, heritability $\left(\mathrm{h}^{2}\right)$, permanent environmental effect $(\mathrm{Vc})$ and repeatability (r) for milk production traits are presented in Table 3. Both heritability and repeatability estimates were different from zero (positive) for all milk production traits and the values were low to moderate. The highest heritability estimate was for DMY $(0.28 \pm 0.05)$ and the lowest was for LL $(0.12 \pm 0.04)$.

Lactation milk yield

The heritability estimates for LMY in the present study (0.24) was close to those reported for the tropical highland of Ethiopian crossbred cattle Demeke et al. (2004) 0.24 and Gebregziabhere et al. (2014) 0.26 for Borana $\mathrm{x}$ HF. The estimated error variance showed higher relative importance compared to additive and permanent environmental effects in this study. The present result was higher than Das et al. (2013) 0.18 and 0.22 for Sahiwal x Holstein and three breed crosses and Haile et al. (2009) 0.1 Ethiopian crossbred dairy cattle. However, it was lower than the report of Gebregziabhere et al. (2013) $0.29 \pm 0.04$ for Ethiopian crossbred cattle and Tadesse (2014) $0.57 \pm$ 0.02 for Borana crosses with HF and Jersey. Differences in the estimates are expected because of differences in populations, estimation methods, mathematical models employed and because of sampling errors. The less favorable environmental condition in the study area lead to higher permanent environmental and error variance resulted to high phenotypic variance, which might have reduced the heritability value of LMY.

Daily milk yield

The estimated heritability coefficient $(0.28 \pm 0.05)$ for DMY from the present study was comparable with the report of Gilbert and Johanne (2009) 0.27 for Ayrshire x Sahiwal x Ankole crossbred in Burundi. Lower value was reported by Demeke et al. (2004) $0.19 \pm 0.03$ and Gebregziabher et al. (2014) $0.26 \pm 0.08$ for varies crossbreds. Higher values were reported by Haile et al. (2009) $0.45 \pm 1.05$, Gorbani et al. (2011) 0.334, Gebregziabher et al. (2013) $0.30 \pm 0.04$ for multibred cattle. Variance due to permanent environmental effects and error variances were important sources of variation and highly influenced on heritability of DMY in the present study.

Lactation length

Heritability of LL was estimated to be $0.12 \pm 0.04$ and in line with the report of Kefena et al. (2011) with 0.14 for Borana crosses with HF and Jersey and Das et al. (2013) 0.11 for three bred crosses in Bangladesh. A substantial variation in heritability for LL was found in different literatures. A higher values were reported by Haile et al. (2009) $0.63 \pm 0.02$, Das et al. (2013) 0.43 for HF x local crosses in Bangladesh and Tadesse (2014) $0.27 \pm 0.03$ for Ethiopian crossbred cattle. The deviation of heritability values of LL from the literature might be a result of the differences in the population structure of the herds, model fitted for analysis, estimation procedures, breed and environment where data was obtained. The lower heritability of LL in this study might be associated with a cumulative effect of inconsistenet management practices and environment on the performance of dairy cows.

Table 3. Estimate of variance components, heritabilities $\left(h^{2} \pm s e\right)$ and repeatabilities $(r \pm s e)$ for productive traits from multivariate analysis.

\begin{tabular}{|l|l|l|l|}
\hline & LMY & DMY & LL \\
\hline $\mathrm{Va}$ & 167616 & 0.98 & 852.23 \\
\hline $\mathrm{Vc}$ & 176184 & 0.65 & 812.53 \\
\hline $\mathrm{Ve}$ & 331404 & 1.90 & 5563.66 \\
\hline $\mathrm{Vp}$ & 675205 & 3.53 & 7228.42 \\
\hline $\mathrm{h}^{2}$ & $0.25 \pm 0$ & $0.28 \pm 0.05$ & $0.12 \pm 0.04$ \\
\hline $\mathrm{r}$ & $0.50 \pm 0$ & $0.46 \pm 0.02$ & $0.23 \pm 0.02$ \\
\hline
\end{tabular}

$\mathrm{Va}=$ additive variance, $\mathrm{Vc}=$ permanent environmental variance, $\mathrm{Ve}=$ error variance, $\mathrm{Vp}=$ phenotypic variance, $\mathrm{h}^{2}$ $=$ heritability and $\mathrm{r}=$ repeatability

\section{Repeatability estimation}

Repeatability estimate for LMY and DMY in the present study were medium (0.50 and 0.46) which indicated that sufficient additive and permanent environmental variance could be favor to repeat the traits for later lactation and inferior animals could be disposed of naturally or artificially on the bases of their early performances. However, the corresponding estimate for LL were low (0.23) which can be accounted for high temporary environmental variance or the reliability of heritability value for repeated performance of LL was low. The repeatability value of LMY was in agreement with the value of Ghorbani et al. (2011) who reported 0.50 for Iranian HF crosses. Lower repeatability values as compared to the present study were reported by Gilbert and Johanne (2009) for DMY (0.36), Gorbani et al. (2011) for LMY and DMY (0.40 and 0.33) and Gebregziabhere et al. (2013) 
for LL (0.21). However, higher repeatability value of milk production traits were estimated by Haile et al. (2009) for DMY and LL (0.54 and 0.7) and Gebregziabhere et al. (2013) for LMY and DMY (0.53 and 0.51), respectively. Genetic and phenotypic correlations

The direct genetic and phenotypic correlations among three milk production traits (LMY, DMY and LL) are summarized in Table 4. The genetic correlations between milk traits in the present study were positive and ranges from low (0.11) to slightly high (0.77). High genetic correlation was observed between LMY and LL (0.77). This value was closely similar with the study by Gebregziabhere et al. (2013) who reported 0.73 correlation between LMY and LL. Furthermore, Das et al. (2013) reported an estimated correlation 0.31 for LMY and LL and 0.30 for LMY and DMY. Haile et al. (2009) reported genetic correlation between LMY and LL (0.55) and between DMY and LL (0.78). Tadesse (2014) also reported moderate to very strong genetic correlation $(0.59,0.96$ and 0.99$)$ between DMY and LL, LMY and DMY and LMY and LL, respectively.

Phenotypic correlation between milk production traits were very low (0.07 between DMY and LMY), low ( 0.18 between DMY and LL) and moderately low ( 0.36 between LMY and LL). The phenotypic correlation between LMY and LL was in agreement with the report of (Das et al., 2013). Relative to the present study, Tadesse (2014) found higher phenotypic correlation between DMY and LL (0.39), DMY and LMY (0.86) and LMY and LL (0.76).

From the result of this study, the genetic correlations among LMY, DMY and LL were higher than their corresponding phenotypic correlations. The different estimate of genetic and phenotypic correlations with that of others literature reported elsewhere could be attributed to differences in sample size, breeds (genetic makeup), models and procedures used to estimate parameters and environments such as feeding, climate and other management practices.

Table 1. Genetic and phenotypic correlations of milk production traits

\begin{tabular}{|l|l|l|l|}
\hline & LMY & DMY & LL \\
\hline LMY & & 0.11 & 0.77 \\
\hline DMY & 0.069 & & 0.54 \\
\hline LL & 0.36 & 0.18 & \\
\hline
\end{tabular}

Genetic correlation (above diagonal) and phenotypic correlation (below diagonal)

\section{Genetic trend}

The overall genetic trend for LMY was non-significant $(\mathrm{p}>0.05)$ and not in the right direction (negative) which indicate that a decreasing in milk yield across the observed years. However, DMY and LL were positive but insignificant which mean that an increasing trend over the observed years (figure1 and 2). Figure1 showed that genetic trend of LMY and DMY were declined at the beginning and increased gradually then to be high around 1994-1995. Then after both traits became decline through recent years. There were a positive genetic trend from 1988-2002, which indicates an increasing breeding value because of use of better dams and sires in that years.

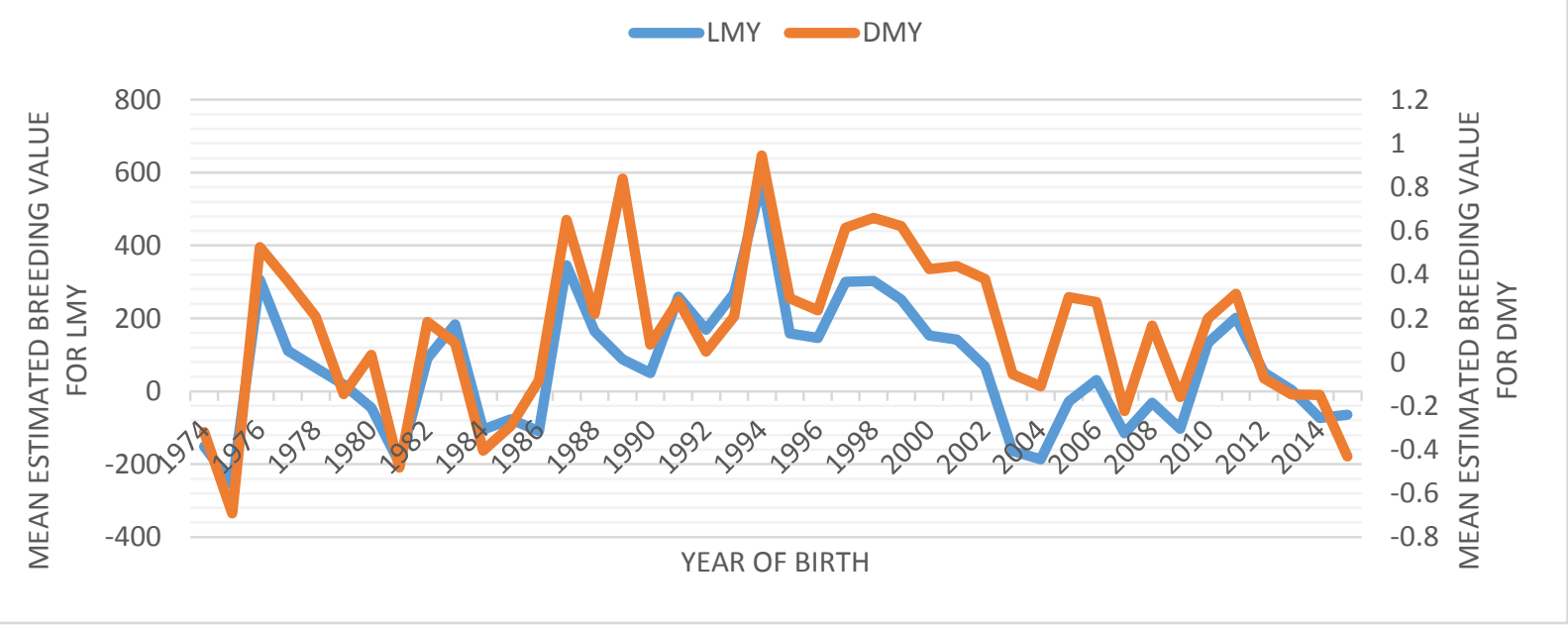

Fig 1. Genetic trend for lactation milk yield and daily milk yield 


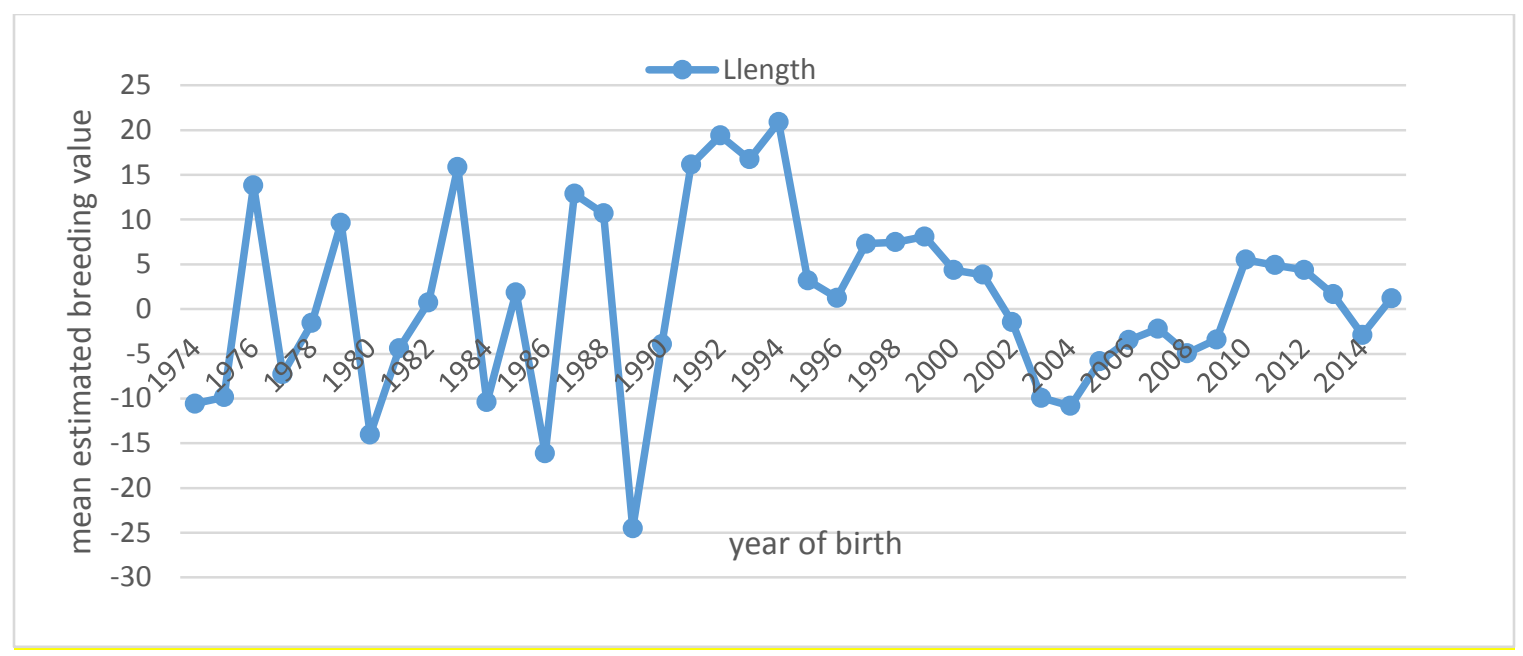

Fig 2. Genetic trend for lactation length

The regression coefficient of mean breeding value for LMY, DMY and LL on year of birth were $0.29 x+651$ liter/year, 0.0015x-2.9 liter/year and 0.038x-74 days/year, respectively. Thus, this means that breeding value for LMY was decreased by 0.3 liter while breeding value of DMY and LL were increased by 0.0015 liter/year and 0.04 days/year, respectively across the study period. This might be the within year difference between estimated breeding value of cows in a particular trait. A negative genetic impact on LMY in this study might slow the favorable genetic response of the herd.

\section{Conclusion}

Both heritability and repeatability values for milk production traits were low to medium but within the range of tropical crossbred estimates. Improving management and feeding in the herd simultaneously could strive the additive genetic variance and ultimately improve these moderate and low heritability, repeatability and breeding values of the herd. The positive genetic correlation among milk yield traits might be important for selection within the population either one or combination of these traits. Selection of dam and sire within this population should very important for the achievement of better genetic gain.

Acknowledgement

This study was done by using long-term crossbred data that is available at Holetta Dairy Research Farm. The authors would like to thank the research farm.

\section{Conflict of Interest Declaration}

The authors declared that no potential conflict of interest is reported regarding the subject matter of this manuscript.

\section{Reference}

1) Albero, M. and Haile-Mariam, S. 1982. The indigenous cattle of Ethiopia. World Animal Review. 41-42: 2-10, 27-24.

2) Aynalem Haile. 2006. Genetic and economic analysis of Ethiopian Borana cattle and their crosses with Holstein Friesian in central Ethiopia. Doctoral Dissertation submitted to National Dairy Research Institute, Karnal (Deemed University), India.

3) Aynalem Haile, Workneh Ayalew, Noah Kebede, Tadelle Dessie and Azage Tegegne. 2011. Breeding strategy to improve Ethiopian Borena cattle for meat and milk production. IPMS (Improving Productivity and Market Success) of Ethiopian Farmers Project Working Paper 26. ILRI (International Livestock Research Institute), Nairobi, Kenya.

4) Chagunda MG, Burns EWCBA, Wollny HM, King. 2004. Effect of milk yield based selection on some reproductive traits of Holstein Friesian cows on large-scale dairy farms in Malawi. Livestock Research for Rural development. 16(7): 89 - 95.

5) Cunningham EP, Syrstand O. 1987. Crossbreeding Bos indicus and Bos taurus for milk production in tropics. FAO (Food and Agricultural Organization of the United Nation) Animal Production and Health paper No. 68 , Rome, Italy. 
6) DAGRIS (Domestic Animal Genetic Resources Information System). 2006. Rege, JEO, Ayalew W, Getahun E, Hanotte $\mathrm{O}$ and Dessie $\mathrm{T}$, (eds). International Livestock Research Institute, Addis Ababa, Ethiopia. http://dagris.ilri.cgiar.org.

7) Das A, Gous Miah, Mukta Das Gupta and Md., Kabiru Islam Khan. 2013. Genetic parameters of Holstein crossbred on commercial dairy farms in Chittagong, Bangladesh. Indian Journal of Animal Research 47 (4): 327-330.

8) Dash SK. AK Gupta Avtar Singh, Pushp Raj Shivahre, Achun Panmei and Manvendra Singh. 2016. Comparative Assessment of Sire Evaluation by Univariate and Bivariate Animal Model for Estimation of Breeding Values of First Lactation Traits in HF Cross Cattle. Indian Journal of Animal Sciences. 86 (2): 177-179.

9) Dechow CD, Rogers GW, Clay JS. 2001. Heritability and correlations among body condition scores, production traits and reproductive performance. Journal of Dairy Science. 84: 266-275.

10) Demeke S, Neser FWC, Schoeman SJ. 2003. Variance components and genetic parameters for early growth traits in a mixed population of purebred Bos indicus and crossbred cattle. Livestock Production Science. 84: 11-21.

11) Demeke Sindros, Neser FWC, Schoeman SJ. 2004. Estimates of genetic parameters for Borana, Friesian and crosses of Friesian and Jersey with the Borana cattle in the tropical highlands of Ethiopia: milk production traits and cow weight. Journal of Animal Breeding and Genetics. 121: 163 - 175.

12) Gebregziabher Gebreyohannes, Skorn Koonawootrittriron, Mauricio A, Elzo and Thanathip Suwanasopee. 2013. Variance components and genetic parameters for milk production and lactation pattern in an Ethiopian multi-bred dairy cattle population. Asian Australas Journal of Animal Science. 26 (9): 1237 - 1246.

13) Gebregziabher Gebreyohannes, Skorn Koonawootrittriron, Mauricio Aguirre Elzo and Thanathip Suwanasopee. 2014. Genotype by environment interaction effect on lactation pattern and milk production traits in an Ethiopian dairy cattle population. Kasetsart Journal of Natural Science. 48: 38 - 51.

14) Getahun K, Tadesse M, Hundie D. 2020. Analysis of Genetic Parameters for Reproductive Traits in Crossbred Dairy Cattle Maintained at Holetta Agricultural Research Center. Asian Journal of Dairy and Food Research. 39(1): 10-16.

15) Getahun K, Hunde D, Tadesse M, Tadesse Y. 2019. Reproductive performances of crossbred dairy cattle at Holetta Agricultural Research Center. Livestock Research for Rural Development. Volume 31, Article \#138. Retrieved August 17, 2020, from http://www.lrrd.org/lrrd31/9/kefa31138.html.

16) Ghorbani AS, Miraii Ashtiani, Salamatdoust Noubr, Agdam shahriar H, Nikzad S. 2011. Estimation of genetic parameter in Iranian Holstein crossbred dairy cattle. African Journal of Microbiology Research. 5 (12): $1568-1570$.

17) Gilbert Hatungumukama, Johanne Detilleux. 2009. Estimation of genetic and crossbreeding parameters for daily milk yield of Ayrshire $\times$ Sahiwal $\times$ Ankole crossbred cows in Burundi. Livestock Science. 122: 359-362.

18) Gorbani AR, Salamatdoust Nobar U, Mehman Navaz J, Gyasi H, Agdam Shahryar K, Nazer AD. 2011. Heritability and Repeatability Estimation in Iranian Brown Swiss Crossbred Dairy Cattle Population. International Journal of Animal and Veterinary Advances. 3(4): 235-237.

19) Haile A, Joshi BK, Workneh Ayalew, Azage Tegegne, Singh A. 2009. Genetic evaluation of Ethiopian Borana cattle and their crosses with Holstein Friesian in central Ethiopia: milk production traits. Animal. 3(4): 486 $-493$.

20) Kefena Effa, Zewdie Wondatir, Tadelle Dessie, Aynalem Haile. 2011. Genetic and Environmental trends in the long-term Dairy cattle genetic improvement programs in the Central Tropical Highlands of Ethiopia. Journal of Cell and Animal Biology. 5(6): 96 - 104.

21) Miglior F, Muir BL, Van Doormaa BJ. 2005. Selection indices in Holstein cattle of various countries. Journal of Dairy Science. 88: 1255-1263.

22) Ojango JM, Malmfors B, Okeyo AM. 2006. AGTR (Animal Genetics Training Resource, version II). International Livestock Research Institute, Nairobi, Kenya and Swedish University of Agricultural Sciences, Uppsala, Sweden.

23) Olawumi SO, Salako AE. 2010. Genetic parameters and factors affecting reproductive performance of White Fulani cattle in southwestern Nigeria. Global Veterinarian. 5 (5): 255 - 258.

24) Rege JEO, Mosi RO. 1989. Analysis of the Kenyan Friesian breed from 1968 to 1984: genetic and environmental trends and related parameters of milk production. Bulletin of Animal Health and Production in Africa. 37:267.

25) Tadesse Birhanu. 2014. Estimation of crossbreeding parameters in Holstein Friesian and Ethiopian Borana crosses for milk production and reproduction traits at Holetta Agricultural Research Center, Ethiopia. MSc Thesis, Haramaya University, Haramaya, Ethiopia. 